\title{
Pseudo-Bartter Syndrome in Chinese Children with Cystic Fibrosis: Clinical Features and Genotypic Findings
}

\author{
Yuelin Shen ${ }^{1}$, xiaolei tang ${ }^{1}$, Jinrong Liu ${ }^{1}$, and Shunying Zhao ${ }^{1}$ \\ ${ }^{1}$ Beijing Children's Hospital
}

May 15, 2020

\begin{abstract}
Objectives: To characterize the clinical and genotypic features of Cystic fibrosis-associated pseudo-Bartter syndrome (CF-PBS) in Chinese children. Methods: We recruited and characterized the clinical manifestations of 11 Chinese children with CF-PBS. Sweat test, blood and urinary analysis, sputum culture, chest and sinus computed tomography, abdominal ultrasonography were obtained. Whole-exome sequencing, bioinformatics analysis, and sanger sequencing validation was performed to define the genotypes. Results: CF-PBS was accompanied by recurrent and/or persistent pneumonia (100\%), pancreatitis (81.8\%), vomit and/or diarrhea (63.6\%), failure to thrive (FTT) (63.6\%) and liver disease $(54.5 \%)$ among our patients. The predominant organisms found in the airways was Pseudomonas aeruginosa (90.9\%) and Staphylococcus aureus (81.8\%). The mean concentration of blood gas and electrolytes were: PH 7.58, bicarbonate $40.8 \mathrm{mmol} / \mathrm{L}$, sodium $126.7 \mathrm{mmol} / \mathrm{L}$, chloride 80.0 $\mathrm{mmol} / \mathrm{L}$, and potassium $2.7 \mathrm{mmol} / \mathrm{L}$, respectively. A high recurrence rate $(54.5 \%)$ of PBS was observed despite continued electrolyte supplementation during follow up. 17 different mutations of CFTR gene were identified, and 9 of them turned out to be novel observations (c.262_266delTTATA, c.579+2insACAT, c.1210-3C>G, c.1733T>C, c.2236_2246delGAGGCGATACTinsAAAAATC, c.3635delT, c.3859delG, c.3964-7A >G and $\Delta$ E23 [c.3718-?_3873+?del]). The c.2909G >A/p.G970D was the most common mutation, with an allele frequency of $18.2 \%$. c.1521_1523delCTT/p.F508del was the first time found with homozygous genotype in patients of Chinese origin. Conclusions: In China, CF-PBS always occurs early and repeatedly in infancy, accompanied by the high frequency of multi-system co-morbidities. Recurring in school-age patients is rare but does exist. The c.2909G>A/p.G970D is the most frequent mutation in Chinese patients with CF-PBS, showing a significant ethnic tendency of Chinese origin.
\end{abstract}

\section{Hosted file}

Manuscript.doc available at https://authorea.com/users/322396/articles/451384-pseudo-barttersyndrome-in-chinese-children-with-cystic-fibrosis-clinical-features-and-genotypicfindings 

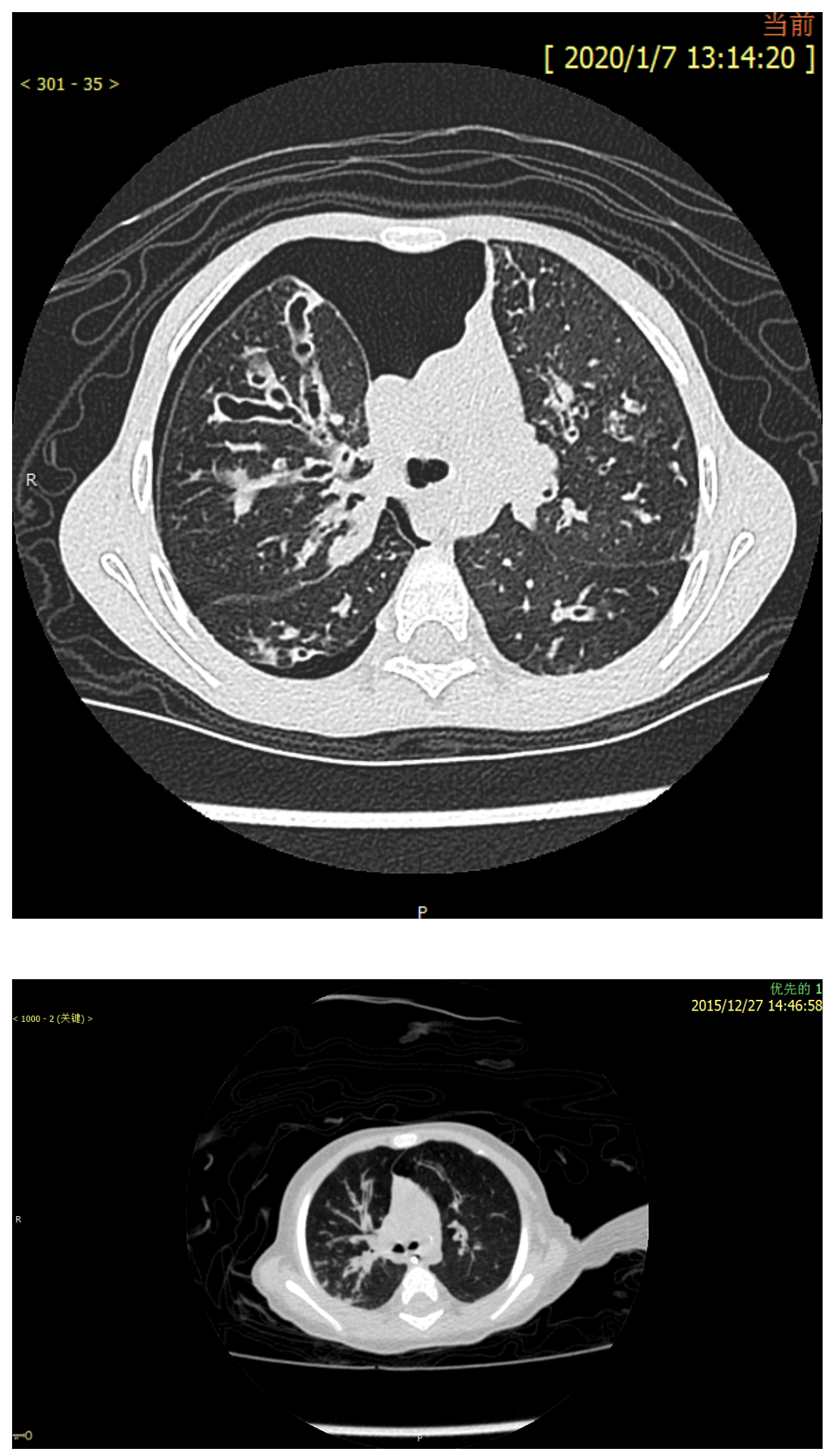


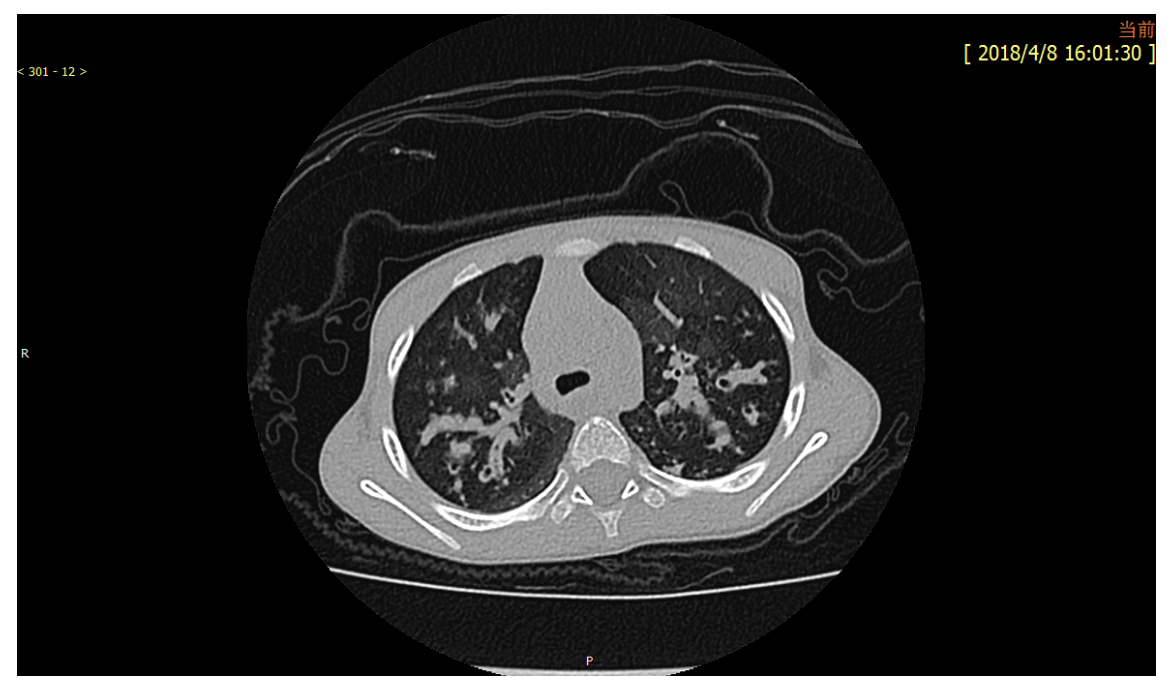

\section{Hosted file}

Table 1.docx available at https://authorea.com/users/322396/articles/451384-pseudo-barttersyndrome-in-chinese-children-with-cystic-fibrosis-clinical-features-and-genotypicfindings

\section{Hosted file}

Table 2.docx available at https://authorea.com/users/322396/articles/451384-pseudo-barttersyndrome-in-chinese-children-with-cystic-fibrosis-clinical-features-and-genotypicfindings

\section{Hosted file}

Table 3.docx available at https://authorea.com/users/322396/articles/451384-pseudo-barttersyndrome-in-chinese-children-with-cystic-fibrosis-clinical-features-and-genotypicfindings 